\title{
2. The puzzling persistence of the intellectual property right/climate change relationship
}

Navraj Singh Ghaleigh*

\subsection{INTRODUCTION}

At the 2011 United Nations Framework Convention on Climate Change (UNFCCC) Conference of the Parties in Durban, India sought to introduce a number of late amendments to the negotiations, including those on technology transfer. Specifically, they wished for the inclusion of the agenda item 'Accelerated access to critical mitigation and adaptation technologies and related intellectual property rights'. Why? They explained that:

An effective and efficient global regime for accelerated access to intellectual property rights (IPRs) of critical climate friendly technologies is essential for the global efforts for development, deployment, dissemination and transfer of such technologies. In the absence of such an arrangement, the objective of advancing the nationally appropriate mitigation and adaptation actions at the scale and speed warranted by the Convention cannot be met effectively and adequately. Such a regime should promote access to IPRs as global public good while rewarding the innovator in a manner consistent with the international law ... Conference of Parties should urgently decide on addressing the issue of treating and delivering climate technologies and their IPRs as public good in the interest of the global goal of early stabilization of climate and advancing developing country efforts aimed at social and economic development and poverty eradication. ${ }^{1}$

Such a statement raises a number of questions. Is it truly the case that liberalized access to climate friendly IPRs is essential for the development and dissemination of such environmentally sound technologies (EST)? In the absence of an IP regime that makes such provision, can nationally appropriate mitigating actions (NAMAs) ${ }^{2}$ not be achieved? 
Should IPRs underpinning EST really be treated as public goods, such as air or national defence, non-rivalrous and non-excludable?

It may be unfair to subject what is essentially a single move in the extended chess game of the UNFCCC negotiations to such scrutiny. Arguments (or rather, claims) of this sort often serve not to divine a deeper truth but to strike a bargaining pose and lay down a marker for a future skirmish. For present purposes the Indian proposal, which was in any event unsuccessful, represents but the latest in a long series of attempts to argue that IPRs are somehow central to the processes of climate change mitigation. As will be argued below in the context of the technology transfer processes of the UNFCCC, to view IPRs as a meaningful barrier to the development and deployment of climate change mitigation technologies is erroneous. This is not to say that the IPR/ climate change relationship is meaningless. Not at all. As the above extract evidences, it clearly means a great deal to certain, recurrent, parties who draw on the symbolic significance of IPRs on a regular basis. Whether or not IPRs are a 'dog whistle' issue - that is, a form of coded language that appears has one meaning to most in an audience but has a different and specific meaning for a targeted subgroup of the audience to certain parties will not be explored herein. Rather, the focus herein is on the more limited question of whether non-liberalized access to climate friendly IPRs is essential for the development and dissemination of such environmentally sound technologies.

The intellectual property and environmental law relationship is not one that has been over-examined. Indexes of the leading texts, whether environmental ${ }^{3}$ or IP, tend only to recognize this relationship in the form of brief references to the TRIPS ${ }^{4}$ agreement and/or biodiversity. ${ }^{5}$ For the specific purposes of climate change, the same pattern of non-treatment has been the norm, with leading works having rather little to say about either IP or technology transfer (TT) more broadly. Very recently, however, a new trend has been discernible in the literature, driven principally by IP lawyers. ${ }^{6}$ Of the various claims being made, ${ }^{7}$ the most important for present purposes is that IPRs may, or even are likely to, function as a significant barrier to TT in the climate change realm. This argument proceeds along the lines that there are novel technologies which hold the key to climate change mitigation, that they may be exploited behind the shield of patent protection and that these monopoly powers maximize the innovator's profit in exploitation whilst restricting deployment. ${ }^{8}$

This chapter commences (section 2.2) with an account of the development of the TT agenda in multilateral environmental agreements (MEAs) and the UNFCCC regime in particular, including the Cancun Accord's 
technology mechanism. The actual operation of TT - its numerous 'pathways' - will briefly be examined. If the worst fears of IP lawyers are correct, TT's position as both the primary facilitator of ESTs and its choke point, requires attention. Section 2.3 looks specifically at the relationship between IPRs and TT in the climate change context. It is notable that whilst climate change lawyers have not opined on this in detail, the literature emerging from the community of IP lawyers certainly does. Their arguments have a variety of strands and those relating to the TRIPS agreement, for example, will not be dealt with (not least because they can be accommodated within existing lines of argument herein), with the focus instead being on the 'impediment' argument. Simply put, as noted by Culver in this collection, this is a claim that climate change mitigation shares many characteristics with the HIV/ AIDS epidemic, and just as IPRs could be subjected to compulsory license arrangements in the latter case, similar arguments apply in the former. This view is challenged on argumentational grounds. Section 2.4 further challenges IP's capacity to operate as an impediment in the climate change context, by reference to the policy literature and to detailed studies of examples of TT between the United Kingdom and India and China, respectively. This more empirical approach places the costs of IPRs in mitigation technologies (such as licensing costs) in the broader context of complete deployment costs, and considers the availability of substitutions and also the role of government support. Only when all these considerations are taken on board, it will be argued, can the role of IPRs in climate change mitigation be assessed with any clarity. Is it pivotal or peripheral?

\subsection{TT AND THE CLIMATE REGIME}

\subsubsection{Operation of TT}

Defined as the 'broad set of processes covering the flows of knowledge, experience and equipment amongst different stakeholders such as governments, private sector entities, financial institutions, non-governmental organizations (NGOs) and research/educational institutions', 9 TT plays an important role in the climate regime and the clean development mechanism (CDM) in particular. ${ }^{10}$ Given that foreseeable growth in global emissions will come predominantly from developing economies, ${ }^{11}$ and that those economies have tended not to have access to the state of the industrial art, TT is one of the key means by which global emission growth can be kept within the bounds of scientifically recommended 
levels. Assuming prompt access to EST, the opportunity would arise for developing economies to leapfrog the resource-intensive and highly polluting phase of industrial development that has characterized much of the North's industrialization since $1750 .{ }^{12}$

Generic TT - that relevant to the diffusion of all technologies, not just those pertinent to climate change mitigation - occurs through a number of established channels which are closely tied to the support provided by international financial flows. These can be categorized as TT via trade, foreign direct investment (FDI) and international programs and development aid, including the World Bank's Global Environment Facility (GEF). ${ }^{13}$ The Kyoto mechanisms function as such channels and are discussed below.

TT through trade, for example, occurs principally through trade in capital or investment goods and may take place by way of licensing or joint venture. ${ }^{14}$ In the former case, this involves the owner of a technology contracting with an entity in the receiving company to use the technology without infringement, in the latter when two (or more) firms agree to work together for mutual benefit. For present purposes, however, as Peterson notes, "the environmental effects of this trade are ambiguous', and actual evidence on the importance of trade for the transfer of energy saving technologies to developing countries and the overall effect of trade on greenhouse gas (GHG) emissions in developing countries is 'scarce'. ${ }^{15}$

What of the power relations between parties to TT arrangements? The assumption that transferee nations (typically those which are Non-Annex I states in the UNFCCC (NAI) would be passive recipients, taking what they are offered, is not supported by recent reports from the energy sector. These suggest the contrary, especially where market power has been used by leading industrializing countries to demand TT arrangements involving cutting edge technologies. The Chinese government is reportedly using its market size to compel foreign companies to part with nuclear knowhow - China being the largest single market for next generation civil nuclear generation. The competition for the concession to build China's third-generation nuclear reactor fleet was won by the US-based Westinghouse because full TT was crucial to the agreement and 'Westinghouse agreed to a technology transfer that was much wider in scope than Areva, and that's why Westinghouse has a larger share of the current capacity construction than Areva'. ${ }^{16}$ Admittedly, such a narrative is premised on the fact of overweening market power which is available only to some developing countries, perhaps the BASIC nations and Mexico. In terms of the relevant technologies, there is evidence of the dynamic of technology acquisition in other low-carbon sectors 
beyond civil nuclear: 'the winning company, Westinghouse, agreed to hand over the plans for its third-generation nuclear reactor as part of the deal. Likewise, with wind energy, local content requirements and joint ventures have allowed Chinese manufacturers to access turbine technologies. ${ }^{17}$

From such reports it appears not only that TT is alive and well in industrial sectors relevant to climate change, but that its dynamics are far removed from that of beneficent donor/grateful recipient. Key actors in the climate change arena are able to deploy their market power effectively so as to access technologies, including highly sensitive technologies such as civil nuclear.

TT by FDI is often preferred to licensing or joint venture agreements by enterprises that wish to have closer control over their technology by investing their own resources. Of the $c$.US $\$ 200$ billion of foreign direct investments made annually, about US $\$ 15$ billion are specific investments in the energy sector in developing and transition countries. ${ }^{18}$ Driven principally by multinational enterprises, 'energy FDI' accounts for sizable percentages of the overall figure: 10 per cent in China and 50 per cent in Latin America (excluding Brazil). ${ }^{19}$ Although the evidence varies, Peterson concludes that the "main result is that foreign ownership is associated both with less energy use as well as with the "cleaner end" of the range of energy types'.$^{20}$

TT not by trade but via international programs and official development assistance (ODA) is well known to environmental lawyers, including as it does aid that is provided through such organizations as the multilateral development banks and the GEF. Although private flows to developing countries are larger than ODA, this has only been the case since the 1990s. ODA is highly relevant to GHG emissions since 40-50 per cent of it is directed towards energy and transport infrastructure. ${ }^{21}$ Traditionally, this has focused on coal-fired generation and large-scale hydro but has increasingly been directed towards geothermal, solar, wind and biomass generation projects. Transport, agriculture, forestry and general environmental protection are also significant beneficiaries. ${ }^{22}$ To the extent that ODA is national (whether bi- or multilateral) and directed towards climate change, developed countries will report it in their national communications to the UNFCCC Secretariat. Some developed country ODA funding is mediated through the GEF, which has since 1991 invested US $\$ 9.2$ billion directly and US $\$ 40$ billion in co-financing, across 2,700 projects in 165 countries. ${ }^{23}$ As a dedicated instrument, GEF 
funding is targeted directly to climate change activities, such as renewable energy projects, energy efficiency and low-GHG energy technologies, which induce longer-term transformations of the market than commercial investments. ${ }^{24}$

\subsubsection{Legal Structure of TT in MEAs}

The diffusion of the 'information necessary to achieve a certain production outcome from a particular means of combining or processing selected inputs' (i.e., technology) ${ }^{25}$ is certainly not a process unique to climate change processes, or even MEAs. TT processes occur both within and outwith international agreements. To the extent that international legal mechanisms do support and stimulate TT, they are closely associated with the New International Economic Order (NIEO) movement ${ }^{26}$ and the gains it made in the 1960s and 70s which contributed in the first instance to the development of a range of soft law instruments supportive of $\mathrm{TT}^{27}$ and Principle 20 of the Stockholm Declaration. ${ }^{28}$ Subsequent milestones of international environmental law, from the Brundtland Report $^{29}$ and the Rio Declaration ${ }^{30}$ to Agenda 21, ${ }^{31}$ have each deployed varying conceptions of TT, each the subject of contestation and critique. ${ }^{32}$

To pick but one example of a TT provision, Article 10A of the Montreal Protocol (as amended), provides that parties will seek 'to ensure: (a) that the best available, environmentally safe substitutes and related technologies are expeditiously transferred to [developing] Parties ... under fair and most favourable conditions' ${ }^{33}$ The motivations, justifications and associated challenges that arose in the context of this provision's agreement are well surveyed by Lawrence. ${ }^{34}$ In assessing the legal impediments to effective transfer in the Montreal Protocol context, he considers IPRs but finds that many pertinent substitutes involve chemicals, the patents of which have long since expired (e.g. propane), or know-how of little commercial value... Only a small proportion of the technology in question concerns patentable chemicals or products ... The restraint in transferring [CFC substitute] technology to developing countries is more financial than legal. ${ }^{35}$

Although this conclusion is not fully argued, it is notable for its attempt to consider the operation of TT, and IPRs in particular, in the context of the range of relevant market considerations. It will be a trope of this chapter that understanding the international legal regime pertaining to TT requires attention being paid to the full range of potential barriers to deployment, both legal and non-legal. 


\subsubsection{TT in the UNFCCC}

The 1990 amendments to the Montreal Protocol creating its Article 10A financial mechanism were intended to be 'without prejudice' to other international environmental negotiations. It is scarcely surprising, however, that there were spillover effects, with ongoing negotiations for what would become the UNFCCC. As Bodansky notes, 'for the most part, the International Negotiating Committee ("INC") ${ }^{36}$ discussions on financial transfers picked up where the negotiations for the London Amendments left off'. ${ }^{37}$ TT's underlying logic - the transfer of resources from developed to developing nations - is embedded in the UNFCCC in various ways additional to $\mathrm{TT}$, not least through the commitment to assist developing nations to meet their compliance and implementation costs ${ }^{38}$ and to meet adaptation costs. ${ }^{39}$ Indeed, Honkonen argues that TT is best seen as a particular instantiation of the UNFCCC's architectural principle, common but differentiated responsibilities (CBDR): 'technology transfer is another form of re-distribution of resources through which the principle of CBDR can be realized'. ${ }^{40}$ The UNFCCC's commitment to providing 'new and additional financial resources to meet the agreed full costs' $^{41}$ of developing country compliance were extracted from developed countries at the cost of all party commitments to report on emissions and the establishment of national institutions to implement the Convention's commitments; a quid pro quo that 'shaped the package that ultimately emerged from the negotiations'. ${ }^{42}$

The UNFCCC's key provisions dedicated to TT are to be found at Articles 4(5) and 12(3). They have their origin in the 'Response Strategies' report of the IPCC's Working Group III that fed into its First Assessment Report of $1990 .{ }^{43}$ Noting that developing country emissions 'are increasing with their population and economic growth' the report argued that 'rapid transfer, on a preferential basis to developing countries of technologies to monitor, limit or adapt to climate change without hindering their economic development is an urgent requirement'. And whilst bilateral and multilateral arrangements were already in existence, that 'these should be strengthened and expanded'. ${ }^{44}$ The report goes on to list the range of impediments to effective TT (high capital costs and the lack of resources, but also shortcomings in host nation institutions, training and social factors), suggesting an even longer list of remedial programmes (the establishment of technology research centres, access to substitute products, pilot transfer programmes, etc.). ${ }^{45}$ Such illustrations contributed to INC negotiations in predictably variegated ways, with Ghana on behalf of the G77 seeking TT on concessional terms, in some cases even arguing for 'assured access to technology [or] compulsory 
licensing' while leading developed nations sought to emphasize the cooperative aspects of transfer and highlight their particular concern over IPR protection. ${ }^{46}$ In the event, these negotiating positions served to cancel each other out with few finding final expression in the UNFCCC, Article 4(5) of which provides that:

The developed country Parties and other developed Parties included in Annex II shall take all practicable steps to promote, facilitate and finance, as appropriate, the transfer of, or access to, environmentally sound technologies and know-how to other Parties, particularly developing country Parties, to enable them to implement the provisions of the Convention. In this process, the developed country Parties shall support the development and enhancement of endogenous capacities and technologies of developing country Parties.

The TT commitments imposed on Annex II parties are both modest and qualified. The relevant technologies need only be 'environmentally sound', rather than the 'best available' or 'appropriate to host country circumstances' ${ }^{\prime 4}$ or 'new and innovative' 48 and are specifically linked to the implementation of developing countries' very limited Convention commitments, as found in Article 4(1), which relate principally to emission monitoring, policy promotion and other broadly termed obligations. The reference to 'endogenous capacities and technologies'49 can also be interpreted as a significant indication of the limit of the provision's ambitions, implicitly rejecting the wide-ranging restructuring of economies from outwith this avenue - an opportunity that some developing economies might have welcomed. Indeed, given the primacy of FDI amongst the channels of TT, it is questionable whether the emphasis on endogeneity is apt.

The language of 'practicable' and 'as appropriate' (for whom?) further dilutes the force of the provision. Elaboration of the terms on which transfer would take place (should they occur under 'fair and most favourable conditions', as in most other MEAs?) ${ }^{50}$ is notable for its absence. Explanations for Article 4(5)'s undemanding nature vary and Bodansky accounts for the UNFCCC's silence on the terms of transfer by reference to IPRs and the developed countries' claim that since most IPRs are privately held, they could not commit to their transfer. ${ }^{51}$ This, of course, is very commonly the situation and where IPRs reside in private/corporate hands, the process of TT is usually structured in the form of a joint venture or licensing agreement. In such 'horizontal' processes the presence of a commercial arrangement is a necessary prerequisite for their transfer. ${ }^{52}$

Bodansky also notes that for reasons of their own, developing countries chose to advance the TT argument at the United Nations Conference on 
Environment and Development (UNCED) rather than the INC, which may explain the thinness of the Convention's commitments. Although those of the Rio Declaration are scarcely more substantial and repeat the emphasis on 'endogenous capacities', there is an additional reference to 'new and innovative technologies'. ${ }^{53}$ More illuminating is the remark that:

A number of Western delegations proposed that the technology transfer provision be a general commitment, applicable to all parties. If this proposal had been adopted, it would have allowed developed countries to argue that developing countries have an obligation to promote technology transfer by creating the proper climate for investment in innovation, i.e. by protecting intellectual property rights. The limitation of the technology transfer commitment to developed countries was thus a victory for developing countries, and may account in part for their moderation on the 'terms of transfer' issue. ${ }^{54}$

These arguments in the INC negotiations culminating in what is now Article 4(5) UNFCCC reveal how TT, climate change and IPRs arguments combine, but also the uses to which they are put, and by whom. In the case of Annex I parties there was the concern that the TT provisions could undermine IPR integrity by way of inadequate protection leading to IPRs being used as a shield against NAI attempts to make those provisions more expansive and intrusive. Similarly, the argument that IPRs are privately held and therefore outside the competence of states parties to diffuse, was an essentially defensive one. Both served to neutralize NAI attempts to place TT on a concessional or even compulsory basis. Conversely, the IPR argument was also deployed as a sword by developed countries arguing that IPRs must benefit from adequate systems of protection and enforcement in developing countries. This appears to have been sufficient, for the purposes of those negotiations, to extract a compromise agreement to drop the key issue of terms of transfer. In each of these examples IPR arguments, whether deployed as a shield or sword, served to dilute the stringency and arguably the effectiveness of the UNFCCC's TT provisions. Notwithstanding the diluting effect in the case of Article 4(5), the offensive use of IPRs arose again in the Conference of the Parties (COP) 7 negotiations, as memorialized in the Marrakesh Accords, in a form of words similar to that noted by Bodansky above. ${ }^{55}$

The parameters of the UNFCCC TT provisions are elaborated in the Kyoto Protocol. ${ }^{56}$ The CDM, notwithstanding the absence of facial references to TT in Article 12, very much has TT amongst its core objectives, with references to TT in Articles 3(14), 10(c), 11(2)(b) and 13(4)(b). In the terms of the preamblar words of the Marrakesh Accords, 
the Conference of the Parties emphasized 'that clean development mechanism project activities should lead to the transfer of environmentally safe and sound technology and know-how'. 57

Detailed connections between the CDM and TT are found in COP/ MOP decisions relating to the project design document, with project participants required to describe precisely how technology will be transferred:

A project design document which shall include the following:

A description of the project comprising the project purpose, a technical description of the project, including how technology will be transferred, if any, and a description and justification of the project boundary. ${ }^{58}$

Indeed, it is by reference to project design documents (PDDs) that policy scholars have been able to analyse the contribution of the CDM to TT, and its patterns. ${ }^{59}$ TT can be classified across CDM projects by their type, the nature of the transfer, the origin of the technology and host country. ${ }^{60}$ As of June 2008, 36 per cent of CDM project PDDs claim some TT, with the contribution of TT ranging from a low rate in the case of mature technologies (cement, fuel switching, fugitive methane) to a higher rate in innovative projects such as agriculture, CCS, HFCs and tidal power. About 70 per cent of technologies originate from Japan, Germany, the United States, France and the United Kingdom. ${ }^{61}$ As for geographical distribution, although it is well known that CDM projects are disproportionately hosted in China, India and Brazil, TT is most likely for projects in Bolivia, Guatemala, Indonesia, Mexico and Vietnam. ${ }^{62}$ Moreover, these patterns are dynamic. Seres et al. note that over its short history, TT claims in the CDM have declined in the largest host countries. China, India and Brazil each have lower TT rates than other countries: 'As more projects of a given type are implemented in a host country, the rate of TT often declines [suggesting] that the transfer of technology spreads beyond the individual CDM projects, which enables later projects to rely more on local knowledge and equipment' ${ }^{63}$

TT accordingly has been present since the beginning of the climate regime, with its role significantly augmented by the Kyoto Protocol and the operation of the CDM. Simultaneously, in the UNFCCC negotiations both TT and IPR have moved from a position of some marginality to one of considerably more importance, not least since the Bali Conference of the Parties. For the purposes of TT, that COP made notable progress in the form of its focus on new institutional mechanisms and finance. In respect of the latter, there was a clear desire expressed by NAI parties for a novel funding mechanism to be operated under the auspices of the 
UNFCCC. The Expert Group on Technology Transfer (EGTT) also saw its mandate extended by five years, with the development of performance indicators to measure progress being emphasized. ${ }^{64}$ The Bali Action Plan $^{65}$ set in motion a negotiating process anticipated to culminate in a comprehensive agreement at COP 15. Notwithstanding the famous failure of Copenhagen, by designating them as one of the four building blocks of the Bali Action Plan, ${ }^{66}$ the TT negotiations have since COP 13 taken place under the mandate of the Ad Hoc Working Group on Long-term Cooperative Action (AWG-LCA) and thereby received a degree of attention and energy it had previously lacked.

\subsubsection{Progress at Cancun}

The Copenhagen Accord gave a prominence to TT that has proved to be ongoing, deciding as it did to establish a technology mechanism 'to accelerate technology development and transfer in support of action on adaptation and transfer that will be guided by a country-driven approach and be based on national circumstances and priorities' ${ }^{67}$ Moreover, prior to the bombastic intervention of the Heads of State in the second week of that COP, state representatives had made notable progress towards a new TT mechanism. That mooted scheme comprised an 'executive committee' of politically appointed country representatives and a 'climate technology centre' of technical experts to lead on capacity building which 'represented a smart compromise between the need for a political body to provide guidance and coordination and a more down-to-earth mechanism with technical experts that can implement solutions' ${ }^{68}$ The much lauded Technology Mechanism of the Cancun Accords has closely mapped that approach. Along with the promising advances on finance, reducing emissions from deforestation in developing countries (REDD+) reporting, developed country targets and developing country actions, the technology mechanism stands as a key development in the UNFCCC negotiations. The bifurcated structure contained in the Copenhagen Accord was carried through in AWG-LCA negotiating texts ${ }^{69}$ and is now found in Chapter 4 of the COP decision..$^{70}$ It provides for a 'Technology Executive Committee' and a 'Climate Technology Centre and Network', although the relationship between them and the financial mechanism are among those many details that remain underdetermined. ${ }^{71}$ What, though, of the role of IPRs in this decision and indeed in future negotiations?

Before examining the details of the decision, it is worth asking what role IPRs have played in TT to date and in particular, whether they have operated as a barrier to deployment. According to Honkonen, 'intellectual property rights form a big part of the answer as to why technology 
transfer has not been as successful as it was expected to be' ${ }^{72}$ This is a potentially important finding, chiming as it does with the argument made by IP lawyers, as will be discussed further in the section below. Unfortunately however, Honkonen's response is rather under-argued, providing little basis either for the proposition that TT has been unsuccessful or that IPRs are to blame. Support for the latter claim may be found in policy analyses of the Cancun Agreements' technology mechanism. According to Morgan, in order to get agreement on the Technology Mechanism, 'Delegates [at Cancun] decided to take one of the most contentious issues, intellectual property rights, off the table.' ${ }^{73}$ Again, intriguing but brief.

A fuller analysis comes from Abdel Latif who notes that 'the issue of IPRs was one of the most divisive in the technology negotiations [and that] there was no reference to IPRs in the final text of the Cancun Agreements' ${ }^{74} \mathrm{He}$ characterizes the debate between developed and developing nations at Cancun as a 'polarized' one in which 'developing countries had pressed for the consideration of IPRs as one of the possible barriers to technology transfer [whilst] developed countries opposed such a view, given the essential role they consider that IPR protection plays in providing incentives for innovation in clean technologies' ${ }^{75}$ As a consequence, 'there was little chance for meaningful discussion based on evidence rather than rhetoric'. This is altogether more revealing, not for the explication of the negotiating positions of the parties, but rather because it suggests that the poses which are struck rely less on fact and analysis than might be hoped. In particular, the absence of detailed consideration of the evidence strongly suggests that this is an issue that has assumed symbolic significance to the negotiations. Whilst it is not possible to see into the minds of negotiators to assess whether or not this is an issue of purely emblematic importance, the balance of this chapter will consider the importance of IPRs to climate change mitigation from the perspective of IP lawyers and, secondly, from an empirical basis.

\subsection{IPRS AND THE CLIMATE REGIME}

\subsubsection{We Are Being Watched: Enter the IP Lawyers}

In its first 20 years, the legal literature on climate change has engaged with IPRs in a relatively light-touch fashion. ${ }^{76}$ The subsequent international environmental law (IEL) literature has further explored the specific issue of TT and IPRs ${ }^{77}$ as well as considering IPRs together with 
questions of trade and investment, ${ }^{78}$ common but differentiated responsibilities, ${ }^{79}$ and broader issues of public international law. ${ }^{80}$ Whilst these discussions do address the relationship in relevant and interesting ways either as a negotiating tool wielded by developed nations against developing ones ${ }^{81}$ or as a constraint on $\mathrm{TT}^{82}$ - the treatment is invariably very brief, only infrequently extending beyond a page. Moreover, the leading climate law works have nothing ${ }^{83}$ (or rather little) ${ }^{84}$ to say on this question. Are we to conclude from this that the IP/climate change relationship is of no legal significance? Whilst climate lawyers have apparently averted their eyes, IP and trade lawyers have in recent years focused on this very question. ${ }^{85}$

The core of the IPR argument is not specific to climate change considerations, but rather one generic to IP debates. Boyle puts it thus:

The goal of creating the limited monopoly called an intellectual property right is to provide the minimum necessary incentive to encourage the desired level of innovation ... IP is a brilliant social invention which presents us with great benefits but also with a multitude of dangers [including the risk that] it will restrict access in ways that discourage 'follow on' innovation [and] establish strong 'network effects' which cause the market to tip over to some inefficient technology. ${ }^{86}$

The concern rests on familiar ideas about the incentive effects of IPRs on innovation ${ }^{87}$ (ensuring that innovators can reap the benefits and recoup the costs of their research and development investments) and considers their impact in the context of 'clean technologies'. ${ }^{88}$ This conventional rationale is balanced against the possibility that 'protection of intellectual property rights might act as an impediment to the acquisition of new technologies and innovations in developing countries ... firms in developing countries may not have the necessary financial means to purchase expensive patented technologies' ${ }^{89}$ According to this argument, IPRs can in certain circumstances act as a barrier to deployment as they vest in their holders the market power to limit the availability, use and development of technologies, all of which may combine in higher acquisition costs. $^{90}$ This argument, which has undoubted intuitive appeal, is subjected to scrutiny below.

The argument is not completely unknown to the climate change literature. Cordonier-Segger and Gehring make it, almost as an aside in the following terms: 'as some have noted, high licensing fees, protected by trade obligations related to IPRs, may also be contributing to the insufficient transfer of technology'. ${ }^{91}$ The supporting footnote (presumably the 'some') is to p. 294 of Miller's chapter on trade and development in Global Climate Change and US Law. ${ }^{92}$ However, in this chapter 
Miller makes no such claim. Cordonier-Segger and Gehring are, thereby, inadvertently giving an early example of the underdetermined nature of the argument.

The debate over cross-border flows of clean technology and IPRs has resonances with the contentious debates surrounding access to HIV/AIDS drugs. The narrative of the HIV/AIDS and expensively exclusionary intellectual property associated with the most effective drugs is well known. The IPRs embedded in these drugs accounted for the majority of the high end-user prices of these drugs and prevented their dissemination to patients in Africa, most particularly. The IPR holders (Western pharmaceutical companies) initially resisted any steps that would weaken their IPRs and in so doing broaden access to the drugs. After a high profile political battle that was damaging to their brand reputations, they granted concessions facilitating broader availability of the drugs. Is this narrative one that is analogous to the climate change/EST context? According to some policy-makers from the emerging economies, it certainly is.

An ongoing example of this tendency is found in the AWG-LCA negotiation text prior to Cancun which sought to deploy mechanisms such as patent pools and compulsory licensing, to clear the channels of TT. But are these cures, much less the underlying diagnosis, apt to climate change mitigation? Are the technologies to deliver us from catastrophic climate change impeded from deployment by IPRs?

\subsection{AN EMPIRICAL APPROACH TO CLIMATE MITIGATION}

\subsubsection{McKinsey Cost Curve: What Does IT Reveal about IPRs?}

The McKinsey cost curve is one of the best-known tools in the climate change policy literature, ${ }^{93}$ setting out the options available to an economy to reduce emissions and costing them. It describes the range of mitigation technologies necessary to avoid global temperature rises above $2^{\circ} \mathrm{C}$ by 2030 (i.e., the annual mitigation of $38 \mathrm{GtCO}_{2} \mathrm{e}$ ), the avoided emissions attributable to each technology and its associated costs. At its core lies the graph in Figure 2.1. The $\mathrm{x}$-axis shows the abatement potential of given activities and the y-axis shows the cost per tonne of $\mathrm{CO}_{2}$ reduced. Of particular significance is the analysis's foregrounding of the necessity of the widest range of mitigation options. Rather than presenting either/or choices between, say, carbon capture and storage (CCS) or nuclear power or REDD+ or biofuels, the McKinsey analysis recognizes that avoiding the 


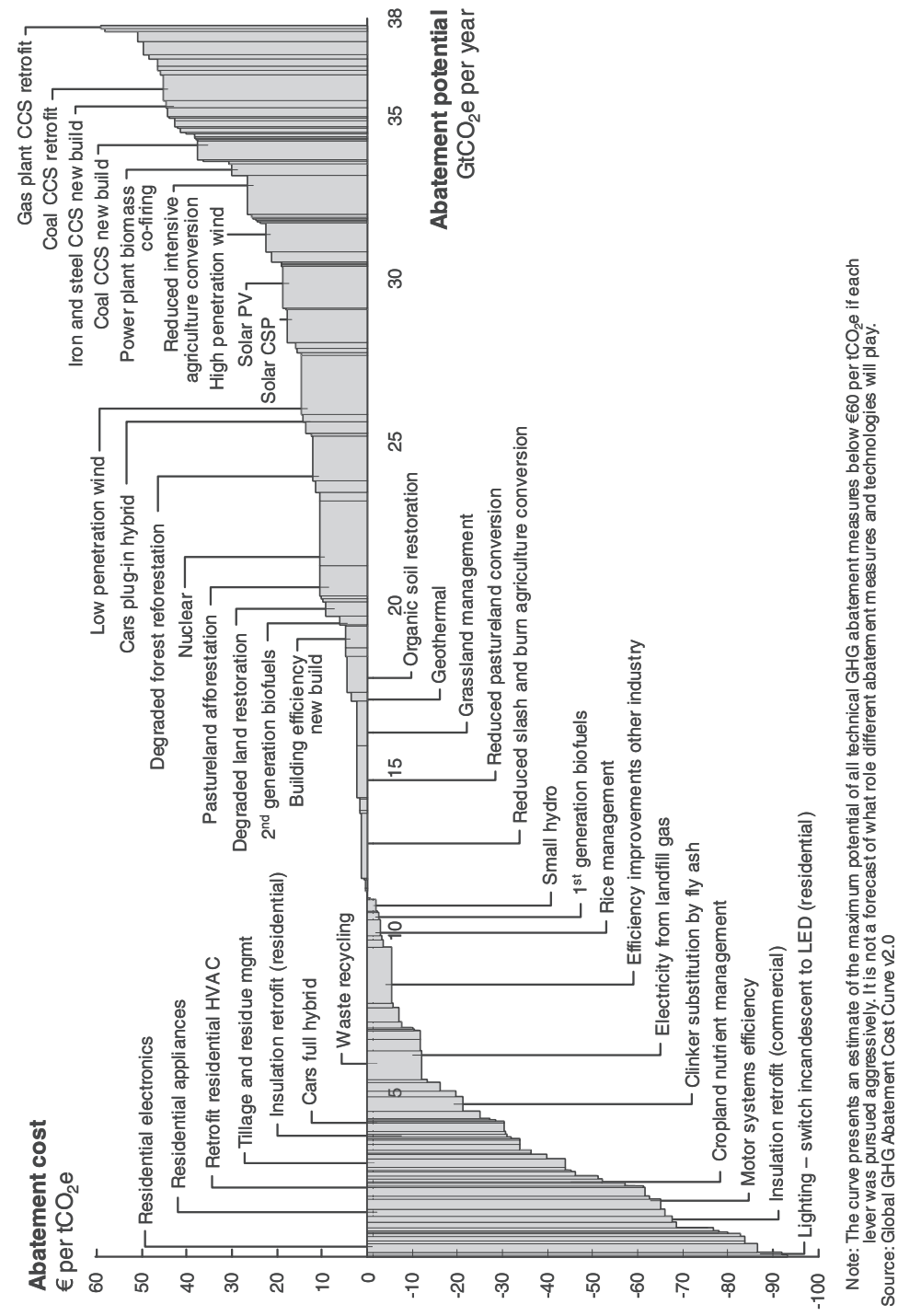

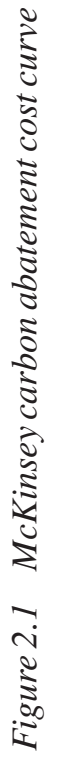


worst of the impacts modeled in the IPCC's Fourth Assessment Report requires the successful deployment of a combination of these technologies, the so-called 'and/and' approach. The opportunities to reduce GHG are ordered by cost, both positive and negative, thus answering the question, 'What are relative costs of various mitigation approaches?' For present purposes its importance lies in providing an empirical means by which the technologies necessary to avoid $2^{\circ} \mathrm{C}$ warming can be identified and, in particular, whether their deployment can be said to be impeded by IPRs.

Such is the McKinsey cost curve's influence that many of its insights have now become 'carbon common sense'. For example, they argue that many technologies to be deployed actually have a negative cost in the sense that their deployment will, over the lifecycle of the product, save money. The most obvious examples are switching from incandescent to LED lighting, building insulation and forms of energy efficiency. These technologies are 'below the line' and are typically those that governments are currently struggling to 'nudge' their citizens and businesses to adopt. ${ }^{94}$ Other sets of technologies will be similarly familiar to climate change experts and have both longer implementation horizons, and being more costly are 'above the line': wind power, forestry/REDD+, advanced biofuels and CCS (both power and industrial).

But what do we learn about IPRs from this combination of mitigation technologies and their associated costs? By revealing the range of technologies necessary to be deployed to avoid warming above $2{ }^{\circ} \mathrm{C}$, the McKinsey cost curve allows us then to examine (a) whether IPRs are present in the necessary technologies, and (b) if 'yes', what their contribution is to the latter's non-deployment.

\subsection{BARRIER TO DEPLOYMENT}

\subsubsection{Regulatory Barriers}

Whilst the remaining discussion herein engages with costs or financial barriers to the deployment of ESTs, with IPRs being amongst those costs, legal and regulatory barriers must also be briefly mentioned. The act of TT requires at least two actors: the provider and receiver. Whether the desired transfer is to occur by way of the technology markets, or FDI or ODA, or any combination of the foregoing, it will be hampered if the legal regime of the receiver either fails to support the transfer or imposes straightforward barriers to it. This odd sounding circumstance is not 
unknown. According to Olawuyi, 'technology transfer to African countries through the CDM portfolio has been difficult because technology transfer laws in most African countries [citing Ghana, Nigeria, Tanzania, Zimbabwe, Kenya and Mozambique] are either archaic or completely silent on the possibility of transferring clean technologies through the CDM' ${ }^{95}$ In the case of Nigeria, it is argued that the protocols of the dedicated government agency to screen technology acquisitions have 'continued to hinder the transfer of useful environmental technologies to Nigeria'. ${ }^{96}$ Other studies show that in two-thirds of developing countries, national laws on TT hinder access to the CDM. ${ }^{97}$ Less baffling but equally deleterious in effect, is that the absence of legal support for TT can operate as a disincentive for investors. Similarly, the absence of a national regulatory framework stymies both investor and regulator awareness of the possibility of mechanisms such as the CDM. ${ }^{98}$ Where such legal barriers operate, non-legal impediments such as inadequate local capacity and knowhow and production base are also often present, and it is to those issues which we now turn.

Is the economic and financial viability of technology deployment influenced by IPRs? As Markusson notes in the context of CCS, these cannot be viewed in isolation but rather together with:

a number of issues, including: carbon prices, inclusion of CCS in EU ETS or other schemes (e.g. CDM), liability rules and future global climate agreements. Carbon pricing is important but so far insufficient and too volatile to guide investment decisions in CCS ... climate policy uncertainty creates a risk premium for CCS power generation investments. ${ }^{99}$

For as long as carbon prices are too weak or too volatile to drive investment decisions, policies such as CCS/renewable obligations, feed-in tariffs, investment support, low-carbon portfolio standards and guaranteed prices will be necessary. ${ }^{100}$ They may be time-limited to early deployment but they will nonetheless serve a key function in cushioning costs. ${ }^{101}$

\subsubsection{A Costs Assessment Framework}

In order to fully locate the role of IPR in climate change mitigation deployment, it is suggested that a series of factors require consideration, individually and collectively. In so doing, this chapter draws on an important paper by the late Professor John H. Barton and seeks to formalize its findings. ${ }^{102}$ Barton notes that there are a wide range of technologies relevant to climate change mitigation, from those necessary 
to make biofuels and clean and renewable electricity (including CCS and nuclear) to those necessary to reduce consumption, both industrial and consumer. These technologies typically benefit from various forms of government encouragement such as subsidies and tax credits for biofuels, feed-in tariffs for renewable energy, support for demonstration projects for low carbon electricity sources, tax incentives for building insulation, and regulatory standards across each of these. As far as IPRs are concerned, each of these technologies has a set of 'typical' patents. In the case of biofuels these include catalysts, processes (nozoenzymes) and standards (Unocal) ${ }^{103}$ for renewable energy they relate to technical improvements (e.g., to turbine blade design or gearing), and so on. Finally, these factors must be collectively analysed in the context of market considerations, see Table 2.1.

Table 2.1 Role of IPR in climate change mitigation

\begin{tabular}{|c|c|c|c|}
\hline Technology sector & Support & $I P R s$ & $\begin{array}{l}\text { Market } \\
\text { considerations } * *\end{array}$ \\
\hline $\begin{array}{l}\text { Building, insulation, } \\
\text { appliances }\end{array}$ & $\begin{array}{l}\text { Regulation, tax } \\
\text { incentives }\end{array}$ & Devices, products & $\begin{array}{l}\text { Low dispersed } \\
\text { costs, small overall } \\
\% \text {, high substitution }\end{array}$ \\
\hline Industrial efficiency & Regulation & Processes & $\begin{array}{l}\text { Industrial } \\
\text { competition so little } \\
\text { tech sharing }\end{array}$ \\
\hline Biofuels & $\begin{array}{l}\text { Levies, credits, } \\
\text { subsidies }\end{array}$ & Catalysts, processes & $\begin{array}{l}\text { High license } \\
\text { incentives, } \\
\text { standards risk, } \\
\text { competition }\end{array}$ \\
\hline RE (wind and solar) & $\begin{array}{l}\text { Levies, credits, } \\
\text { feed-ins, subsidies }\end{array}$ & $\begin{array}{l}\text { Technical } \\
\text { improvements }\end{array}$ & $\begin{array}{l}\text { Government } \\
\text { interests, licensing } \\
\text { costs reasonable }\end{array}$ \\
\hline $\begin{array}{l}\text { Thermal power / } \\
\text { CCS }\end{array}$ & $\begin{array}{l}\text { Regulation, } \\
\text { demonstrators }\end{array}$ & Processes, catalysts & $\begin{array}{l}\text { Government } \\
\text { interests, licensing } \\
\text { costs reasonable }\end{array}$ \\
\hline
\end{tabular}

Taking the factors in Table 2.1 together and applying them in the context of solar PV, biofuels and wind, the argument is that the fears that IPRs operate as barriers to deployment are somewhat overblown. On the contrary, it is argued that IPRs serve a useful dual role. By providing 
protection to innovators, patents provide both encouragement for investment in research and incentives to adopt technologies. Typically this occurs through the licensing arrangements which disseminate given technologies at fees which are (Barton concludes) normally small compared with the other costs of technology deployment. Indeed, the operation of state support in many of the relevant industries and sectors serves to considerably lessen licensing costs. Moreover, in sectors such as building insulation, IPRs comprise a very small part of overall deployment costs, the relevant technologies are often 'off patent' and where that is not the case, there is commonly a high substitution rate between different technologies. These factors are above and beyond tax incentives that states commonly provide for deployment. In such cases, a costs assessment reveals IPRs to be a very low dispersed cost and, as such, scarcely a barrier at all. In cases such as industrial efficiency, competition between market actors is such that there is rather little technology sharing. Such situations may present the case for compulsory licensing schemes, most likely in the fuel or industrial process sectors, but even here problems may be resolved by competition or patent enforcement principles. Moreover, as innovation in such sectors is commonly subsidized by government, they have a significant interest in requiring the wide sharing of technologies they have supported. CCS has precisely these characteristics.

For such arguments to be fully substantiated, there is a need for close, technology-specific, ${ }^{104}$ jurisdiction-by-jurisdiction, analysis of the sort that has scarcely been undertaken to date. ${ }^{105}$

\subsection{CONCLUSIONS}

Recent work strongly suggests that, for the purposes of EST, IPRs have a relatively peripheral role in deployment and certainly do not operate as a barrier. Levi et al. ${ }^{106}$ have noted that while the climate change negotiations have been used:

to push the developed countries to relax their patent rules [they] have responded by arguing that poor intellectual property protection is actually a major reason that clean technology does not spread more quickly ... Unlike in the case of HIV/AIDS drugs, the patents that protect intellectual property are only a small part of the cost of essentially all clean-energy technologies. Relaxing them would not do much to change total costs in most cases. 
In a similar vein, a detailed and important study authored by Watson has concluded that:

Access to intellectual property rights (IPRs) is not a fundamental barrier to the development of low carbon innovation capabilities in China ... this does not mean that IPR issues are unimportant or that options to improve IPR access within developing countries should be excluded from the UNFCCC talks ... the resources required to identify, acquire and assimilate low carbon technologies slowed the development of capabilities and/or diffusion of some of these technologies. ${ }^{107}$

Similarly, trends in the United Kingdom suggest that where public support for research and development is present, an openness of approach is required by the funders. Anecdotally, in the earth observation community, it is generally accepted that post- 'Emailgate', research outcomes and methods must be open to public scrutiny in a way that they were not previously. For that work which relies on IPRs and public support, the trend is increasingly to err on the side of openness and forgo whatever benefits were afforded by IPRs. More formally, much the same tendency is written into government policy regarding large-scale publicly funded demonstration projects of carbon capture and storage. In these, companies in the government's 'competition' for support (up to a value of $£ 1$ billion), are expected to share the full range of information and results accrued from their demonstrators. According to the UK's Department for Energy and Climate Change:

The Government is committed to disseminating the knowledge from the UK CCS demonstration competition to facilitate further commercial scale CCS projects, in the UK and internationally by: demonstrating the full chain of CCS at a commercial scale to show other governments that it can be done; and enabling subsequent projects in the UK and overseas to learn from the experience of the Programme. ${ }^{108}$

These conclusions chime with the costs assessment framework above and take issue with the gloomy predictions of many in the IP community. As Barton notes, in certain significant cases (wind, solar PV, biofuels) IP barriers to deployment appear low. Licensing costs appear small compared with other deployment costs and incentive creation seems more important than IPR issues in technological adoption and transfer. The prevalence of substitutions militates against compulsory licensing, as may competition concerns.

However, this view is not at all shared by those legal scholars working in the field (overwhelmingly IP scholars) or indeed by NAI negotiators, who continue to contest with some vigour the status of IPRs in the 
proposed TT mechanism. ${ }^{109}$ Is this owing to the symbolic status of IPRs and TT to these parties? Are the battles initially commenced in the NIEO debates still to be fought? Does a lagging, historical, conception of IPRs as an Annex 1/NA1 point of conflict continue to dominate negotiations, without, as Latif argues, an empirical basis? Notwithstanding the need for future detailed tech-by-tech, region-by-region research, that would appear to be the case.

\section{NOTES}

* This chapter draws upon and updates my previously published article, 'Barriers to climate technology transfer: The chimera of intellectual property rights' (2011) Carbon and Climate Law Review 220. Sincere thanks to Dr Abbe Brown for her generous support and prompting.

1. Proposals by India for inclusion of additional agenda items in the provisional agenda of the 17th session of the Conference of the Parties, 21 September 2011, FCCC/CP/ 2011.INF.2 (emphasis added).

2. Within Appendix II of the UNFCCC.

3. See P. Birnie, A. Boyle and C. Redgwell, International Law and the Environment (Oxford University Press, Oxford, 2009) 801-9.

4. See P. Cullet, 'Common but differentiated responsibilities' in M. Fitzmaurice, D.M. Ong and P. Merkouris (eds), Research Handbook on International Environmental Law (Edward Elgar, Cheltenham, 2010) 168.

5. See R. Nayar and D.M. Ong, "Developing countries, "development" and the conservation of biological diversity' in M.J. Bowman and C. Redgwell (eds), International Law and the Conservation of Biological Diversity (Kluwer Law International, London, 1996) 235-53. A notable exception is the very good discussion in T. Honkonen, The Common But Differentiated Responsibility Principle in Multilateral Environmental Agreements: Regulatory and Policy Aspects (Kluwer Law International, The Hague, 2009) 170-78.

6. See section 2.3 below.

7. One of the less convincing arguments in this vein is that the 'extraordinary release of GHGs in the earth's atmosphere may be due in major part to our patent laws', E. Derclaye, 'Should patent law help cool the planet? An enquiry from the point of view of environmental law' (2009) 5 International Energy Law Review 186.

8. See e.g., K.E. Maskus and R.L. Okediji, Intellectual Property Rights and International Technology Transfer to Address Climate Change: Risks, Opportunities and Policy Options, ICTSD Programme on IPRs and Sustainable Development, Issue Paper 32 (December 2010).

9. B. Metz and O. Davidson, Methodological and Technological Issues in Technology Transfer, Special Report of IPCC, Working Group III (Cambridge University Press, Cambridge, 2000).

10. See S. Seres, E. Haites and K. Murphy, 'Analysis of technology transfer in CDM projects: an update' (2009) 37 Energy Policy 4919; A. Dechezlepêtre, M. Glachant and Y. Ménière, 'Technology transfer by CDM projects: a comparison of Brazil, China, India and Mexico' (2009) 37 Energy Policy 703, and the references therein.

11. International Energy Agency, World Energy Outlook 2009 (OECD/IEA, Paris, 2009). 
12. B. Lee, L. Lliev and F. Preston, Who Owns Our Carbon Future? Intellectual Property and Energy Technologies, Chatham House Report (September 2009), available at www.chathamhouse.org/publications/papers/view/109124.

13. For a fuller discussion, see S. Peterson, 'Greenhouse gas mitigation in developing countries through technology transfer?: a survey of empirical evidence' (2008) 13 Mitigation and Adaptation Strategies for Global Change 283, and references therein.

14. K. Saggi, 'Trade, foreign direct investment, and international technology transfer: a survey’ (2002) 17(2) World Bank Res. Obs. 191.

15. Peterson, n. 13 above, at 289-90.

16. 'The world's biggest market but in need of nuclear know-how', Financial Times, 20 October 2010.

17. L. Hook, 'Dual approach seeks power security and emission cuts', Financial Times, 27 October 2010.

18. Peterson, n. 13 above, at 301.

19. Ibid. 291.

20. Ibid. 293.

21. J. Ellis, J. Corfee-Morlot and H. Winkler, Taking Stock of the Progress Under the Clean Development Mechanism (CDM), OECD Paper COM/ENV/EPOC/IEA/ SLT(2004)/ FINAL (Paris, 2004).

22. Peterson, n. 13 above, at 296.

23. Global Environment Facility, Behind the Numbers: A Closer Look at GEF Achievements (2010).

24. Peterson, n. 13 above at 298.

25. See M. Blakeney, 'Technology transfer' in P. Cane and J. Conaghan (eds), New Oxford Companion to Law (Oxford University Press, Oxford, 2008) 1158.

26. See the account in M. Bulajic, Principles of International Development Law: Progressive Development of the Principles of International Law Relating to the New International Economic Order (Martinus Nijhoff, Dordrecht, 1986).

27. See, in particular, the Charter of Economic Rights and Duties of States, A/RES/29/ 3281 (1974), Art. 13; and the Declaration on the Establishment of a NIEO, A/RES/S-6/3201 (1974), Art. 4(p).

28. 'Environmental technologies should be made available to developing countries on terms which would encourage their wide dissemination without constituting an economic burden on the developing countries.'

29. Report of the Bruntland Commission (Oxford University Press, Oxford, 1987) 87.

30. Rio Declaration on Environment and Development, Rio, Brazil, June 1992, Principle 9 UN Doc. A/CONF.151/26.

31. Agenda 21, Rio, Brazil, June 1992, Chapter 34, para. 14(b), UN Doc. A/CONF.151/ 26.

32. See, in particular, D. French, 'Developing states and international environmental law: the importance of differentiated responsibilities' (2000) 49 ICLQ 35.

33. Montreal Protocol on Substances that Deplete the Ozone Layer, A Protocol to the Vienna Convention for the Protection of the Ozone Layer, 16 September 1987, entered into force on 1 January 1989, Art. 10A.

34. P. Lawrence, 'Technology transfer funds and the law: recent developments to the Montreal Protocol on Substances that Deplete the Ozone Layer' (1992) 4(1) Journal of Environmental Law 16 at 18.

35. Ibid. 20, 21 and 22.

36. Intergovernmental Negotiating Committee for a Framework Convention on Climate Change, established in December 1990 by the UN General Assembly.

37. D. Bodansky, 'The United Nations Framework Convention on Climate Change: a commentary' (1993) 18 Yale Journal of International Law 451. 
38. United Nations Framework Convention on Climate Change (UNFCCC) 1771 UNTS 107, Art. 4(3).

39. Ibid. Art. 4(4), a provision demanded not by the generality of developing countries but the Alliance of Small Island States (AOSIS) parties in particular. It is notable that as compared with the preceding paragraph, its terms of funding are rather unspecified.

40. Honkonen, n. 5 above, at 170 .

41. UNFCCC, Art. 4(3).

42. See Bodansky, n. 37 above, at 524 .

43. Climate Change: The IPCC Response Strategies, WMO/UNEP IPCC (1990).

44. Ibid. 225.

45. Ibid. 226-7.

46. See Bodansky, n. 37 above, at 530 .

47. A standard proposed by Sri Lanka in AWG-LCA negotiations in 2008, cited in Honkonen, n. 5 above.

48. The formulation found in Principle 9 of the Rio Declaration, n. 30 above.

49. Ibid.

50. Honkonen, n. 5 above, at 175.

51. Bodansky, n. 37 above, at 530.

52. T. Forsyth, Partnerships for Technology Transfer: How Can Investors and Communities Build Renewable Energy in Asia?, Chatham House Briefing Paper SDP BP 05/01 (February 2005).

53. Rio Declaration, n. 30 above, Art. 9.

54. Bodansky, n. 37 above, at note 474.

55. ' $[\mathrm{T}] \mathrm{o}$ improve, as appropriate, the enabling environment for the transfer of environmentally sound technologies through the identification and removal of barriers, including, inter alia, strengthening environmental regulatory frameworks, enhancing legal systems, ensuring fair trade policies, utilizing tax preferences, protecting intellectual property rights ... in order to expand commercial and public technology transfer to developing countries.' Decision 4/CP.7, Annex: Framework for meaningful and effective actions to enhance the implementation of Article 4, paragraph 5, of the Convention, at para. 14(a) (emphasis added).

56. See also Kyoto Protocol (1998) to the United Nations Framework Convention on Climate Change 2303 UNTS 148, Arts 3(14), 10(c), 11(2)(b) and 13(4)(b).

57. Preamble to the Marrakesh Accords, 17/CP.7, adopted at COP 7 in Marrakesh in 2001.

58. Dec. 4/CMP.1, Annex, Appendix B, para. 2 (emphasis added).

59. See n. 10 above.

60. See n. 10 above, and more generally, UNFCCC, The Contribution of the CDM Under the Kyoto Protocol to Technology Transfer (November 2010).

61. Seres et al., n. 10 above, at 4920-22.

62. Ibid.

63. Ibid. 4924.

64. Recognition of the importance of these steps can be found in the efforts made by regional instruments, such as the Niue Declaration on Climate, adopted by the Pacific Island Forum in 2008, to dovetail with the Bali Action Plans TT provisions. See E. Kwa, 'Climate change and indigenous peoples in the South Pacific: the need for regional and local strategies' in B.J. Richardson et al., Climate Law and Developing Countries: Legal and Policy Challenges for the World Economy (Edward Elgar, Cheltenham, 2009) 118.

65. Dec. 1/CP.13, Bali Action Plan, UN Doc. FCCC/CP/2007/6/Add.1.

66. Along with the shared vision for long-term cooperative action, enhanced action on adaptation, and enhanced action on mitigation. 
67. Copenhagen Accord, UN Doc. FCCCC/CP/2009/L.7 (18 December 2009). See also C. Gerstetter, D. Marcellino and E. von Sperber, 'Technology transfer in the international climate negotiations: the state of play and suggestions for the way forward' (2010) CCLR 5.

68. L. Tawney and L. Weischer, From Copenhagen to Cancun: Technology Transfer (World Resources Institute, 10 May 2010), available at http://tinyurl.com/32v3yef.

69. FCCC/AWGLCA/2010/14, 13 August 2010.

70. UNFCCC, Decision 1/CP.16, 'Outcomes of the Work of the Ad Hoc Working Group on Long Term Cooperative Action Under the Convention', ch. IV, B.

71. See generally, J. Morgan, 'Reflections on the Cancun Agreements' (World Resources Institute, 2011).

72. Honkonen, n. 5 above, at 173.

73. See n. 71 above.

74. A.A. Latif, The Climate Technology Mechanism: Issues and Challenges, ICTSD Information Note No. 18 (March 2011).

75. Ibid.

76. See e.g., the discussion of TT and IPRs in Bodansky, n. 37 above.

77. Lawrence, n. 34 above, 16.

78. M.-C. Cordonnier Segger and M. Gehring, 'Trade and investment implications of carbon trading for sustainable development' in D. Freestone and C. Streck (eds), Legal Aspects of Carbon Trading (Oxford University Press, Oxford, 2009), esp. $102-5$.

79. French, n. 32 above, at 35 and Honkonen, n. 5 above.

80. P. Cullet and A. Gowlland-Gualtieri, Key Materials in International Environmental Law (Ashgate, Aldershot, 2004) and L. Boisson de Chazournes, 'Technical and financial assistance' in D. Bodansky, J. Brunée and E. Hey (eds), The Oxford Handbook of International Environmental Law (Oxford of University Press, Oxford, 2007).

81. Bodansky, n. 37 above.

82. Lawrence, n. 34 above, at 21.

83. D. Freestone and C. Streck, Legal Aspects of Implementing the Kyoto Protocol Mechanisms (Oxford University Press, Oxford, 2005).

84. Cordonnier Segger and Gehring, n. 78 above, at 102-5.

85. See WTO/UNEP, Trade and Climate Change (WTO, 2009) 42-5; I. Harvey, Intellectual Property Rights, the Catalyst to Deliver Low Carbon Technologies: Breaking the Climate Deadlock, Briefing Paper (Climate Group, 2008); International Centre for Trade and Sustainable Development (ICTSD), Climate Change, Technology Transfer and Intellectual Property Rights (Copenhagen Economics, 2008); E. Derclaye, 'IPRs and global warming' (2008) 12 Marquette Intellectual Property Law Review 263; E. Derclaye, 'Patent law's role in the protection of the environment: re-assessing patent law and its justifications in the 21st century' (2009) International Review of Intellectual Property and Competition Law 249; Gerstetter et al., n. 67 above; R.K. Srinivas, Climate Change, Technology Transfer and IPRs, RIS Discussion Papers (2009); M. van Hoorebeek and W. Onzivu, 'The eco-patents common and environmental technology transfer: implications for efforts to tackle climate change' (2010) Carbon and Climate Law Review 13; C. Hutchison, 'Does TRIPS facilitate or impede climate change technology transfer into developing countries?' (2006) 3 Law \& Technology J 517.

86. J. Boyle, The Public Domain: Enclosing the Commons of the Mind (Duke UP, Durham, NC, 2008) 63, 68.

87. A. López, 'Innovation and appropriability, empirical evidence and research agenda' in World Intellectual Property Organization (WIPO), The Economics of Intellectual 
Property, Suggestions for Further Research in Developing Countries and Countries with Economies in Transition (WIPO, 2009) 1-40.

88. Harvey, n. 85 above.

89. WTO/UNEP, Trade and Climate Change (WTO, Geneva, 2009) xi.

90. Hutchison, n. 85 above; M. Littleton, The TRIPS Agreement and Transfer of Climate-Change-Related Technologies to Developing Countries, UNDESA Working Paper 71, ST/ESA/2008/DWP/71 (2008).

91. Cordonnier Segger and Gehring, n. 78 above, at 104.

92. M. Gerrard, Global Climate Change and US Law (American Bar Association, 2007).

93. McKinsey \& Co., Pathways to a Low Carbon Economy: Version 2.0 of Global Greenhouse Gas Abatement Cost Curve (2009) 7.

94. The cost of implementation is not taken into account by McKinsey and is one of the many bases on which the analysis has come under criticism.

95. D.S. Olawuyi, 'Beautifying Africa for the Clean Development Mechanism: legal and institutional issues considered' in B.J. Richardson et al., Climate Law and Developing Countries: Legal and Policy Challenges for the World Economy (Edward Elgar, Cheltenham, 2009) 273.

96. Ibid. 279.

97. S. Silayan, Equitable Distribution of CDM Projects Amongst Developing Countries (2006) 10, cited in Olawuyi, n. 95 above.

98. W.K. Agyemang-Bonsu, Ghana's Technology Transfer Needs Assessment: Reporting on Scoping Phase (2002) 7, cited in Olawuyi, n. 95 above.

99. N. Markusson, F. Kern and J. Watson, 'A socio-technical framework for assessing the viability of CCS technology' (2012) Technological Forecasting and Social Change 1.

100. J. Meadowcroft and O. Langhelle, 'The politics and policy of carbon capture and storage' in J. Meadowcroft and O. Langhelle (eds), Caching the Carbon: The Politics and Policy of Carbon Capture and Storage (Edward Elgar, Cheltenham, 2009) 9.

101. J. Stephens and R. Van der Zwaan, 'The case for carbon capture and storage' (2005) 22(1) Issues in Science and Technology 68.

102. J.H. Barton, Intellectual Property and Access to Clean Technologies in Developing Countries: An Analysis of Solar Photovoltaic, Biofuel and Wind Technologies, ICTSD Issue Paper 2 (2007).

103. US Federal Trade Commission, In the matter of Union Oil Company of California, Docket 9305 (2005), cited ibid.

104. The author is considering the UK CCS industry in this respect in a forthcoming work, co-authored with Rudra Kapila.

105. See, however, the report of the Sussex Energy Group and Tsinghua University on the role of TT in fostering innovation, with case studies on energy efficiency in the cement industry, highly efficient coal-fired power generation, electric vehicles, and offshore wind power. J. Watson, UK-China Collaborative Study on Low Carbon Technology Transfer: Final Report to the Department of Energy and Climate Change (2011), available at www.sussex.ac.uk/sussexenergygroup/research/grow thinnovationdevelopingcountries/ukindiacollaberationjim.

106. M. Levi et al., 'Globalizing the energy revolution', Foreign Affairs, November 2010.

107. See n. 105 above, at 52.

108. Full information from the initial 'FEED' studies ('Front-End Engineering and Design') is available at www.decc.gov.uk/en/content/cms/emissions/ccs/demo_prog/ feed/feed.aspx.

109. For details see n. 74 above. 